\title{
LOS MANUSCRITOS CONFESIONALES. UN ACERCAMIENTO A LA MÍSTICA NOVOHISPANA
}

\author{
Rosalva LORETO LÓPEZ ${ }^{1}$
}

\begin{abstract}
RESUMEN: Se propone el estudio de los manuscritos confesionales generados en la Nueva España a lo largo de los siglos XVII y XVIII dentro de la tendencia espiritual que justificó también la aparición de biografías, autobiografías, diarios o conjuntos epistolares asociados con la vida monástica. Estos textos fueron el resultado de prácticas confesionales que formaban parte de un sistema de relaciones de comunicación compartidas en las que al confesor le correspondió transmitir un sistema doctrinal organizador de los sentidos, los sentimientos y las emociones resaltando el papel del cuerpo y el alma en su posibilidad de vehículo trascendente.
\end{abstract}

PALABRAS CLAVE: Mística, ascética, confesor, monjas, cuerpo, demonio.

ABSTRACT: The study of the confessional manuscripts produced in New Spain through the XVII and XVIII centuries is proposed within the spiritual tendency that also justified the apparition of biographies, autobiographies, diaries or epistolaries associated with the monastic life. These texts were the result of confessional practices that formed part of a shared communicative system in which the confessor had to transmit an organizing doctrinal schema of senses, feelings and emotions emphasizing the role of the human body and the soul as a possibility of a transcendental route.

KEYWORDS: mystic, ascetics, confessor, nuns, body, demon.

Los manuscritos confesionales generados en la Nueva España a lo largo de los siglos XVII y XVIII forman parte de la tendencia espiritual que justificó la aparición de biografías, autobiografías, diarios o conjuntos epistolares asociados con la vida monástica. El estudio de estos cuerpos documentales sugiere estar atentos a los mecanismos de su producción y esto nos remite a reconocer además de su simultaneidad temporal, su paralelismo con la corriente cultural europea ligada a la modernidad editorial de las "vidas" ejemplares. En este sentido, otra característica compartida en ambos continentes fue que los textos redactados y editados sobre monjas y beatas visionarias fueron escritos por miembros

${ }^{1}$ Profesor-Investigador del Instituto de Ciencias Sociales y Humanidades de la Benemérita Universidad Autónoma de Puebla (México). 
masculinos ajenos a su misma orden. ${ }^{2}$ Y en este sentido, en el Nuevo Mundo, los jesuitas desempeñaron un importante papel.

Inspirados en el humanismo renacentista, los miembros de la Compañía de Jesús realizaron parte de su importante labor formativa como confesores y guías espirituales $^{3}$ de mujeres criollas dentro de los monasterios. ${ }^{4}$ Añadiendo en algunos casos, la dirección especial de monjas y beatas novohispanas, destacadas visionarias o excepcionales místicas. ${ }^{5}$

A partir del primer tercio del sigo XVII, el trabajo realizado por ellos en el transcurso de las vidas de estas religiosas incluyó, como parte quizás del método de cuidado doctrinal, la labor de ordenar la escritura o proceder ellos mismos a la

2 De manera similar, sucedió en el caso francés, por ejemplo de la hermana María de la Encarnación, religiosa conversa y fundadora de la orden de Nuestra Señora del Monte Carmelo en Francia, se reconocen tres ediciones de su vida; la primera data de 1622 por André Duval, doctor de la Sorbona, la segunda del barnabita Maurice Marín de 1642 y finalmente la editada en 1666 por Daniel Hervé un hermano oratoriano. Véase SUIRE, E. (2001). "La sainteté Carmélitaine d'après la littérature hagiographique de XVIIIe-XVIIIe Siècles". Carmes et Carmelites en France du XVIIe siècle a nos jours. Lyon: Actes du Colloque de Lyon (25-26 septembre , 1997), pp.171-189.

3

De manera muy especial GodínEz, M. (1761). Dedica el Libro Séptimo de su tratado al magisterio espiritual véase, Práctica de la Theología Mystica. Pamplona: En la oficinas de los Herederos de Martínez; RANF, P. (2000). A Woman's Way, The forgotten History of Women Spiritual Directors. New York:Palgrave, pp. 107 y ss. La autora plantea las diferencias entre el confesor y el director espiritual como una de las claves para entender el desarrollo de la mística moderna, asociada ésta al modelo teresiano que le da a la confesión un papel de primer orden, propuesta sugerida por San Francisco de Sales y San Juan de la Cruz. De manera coincidente con esta propuesta, nos centramos en la labor de la confesión como parte de la didáctica de la salvación desarrollada por la dirección de espirítus de la que forma parte indisociablemente.

${ }^{4}$ Un destacado representante de esta labor fue la del padre Antonio Núñez de Miranda (16181695) quien fue confesor y director espiritual de las monjas de los conventos de San Lorenzo donde orientó de manera cercana y no siempre flexible a Sor Juana. La misma función la desempeñó en el monasterio de Nuestra Señora de Balvanera. Además reunía fondos para pagar las dotes de las jóvenes novicias de esas casas. Brading, D.( 2001). "La patria criolla". Colegios Jesuitas, México: Editorial Artes de México, Revista-libro, Núm.58, p.64.

${ }^{5}$ En Hispanoamérica muchas mujeres muestran a través de sus escritos que fueron visionarias, pero muy pocas fueron místicas en último grado. Las visiones fueron consideradas símbolos de fe personal y se interpretaron como formas de acercamiento a Dios, como un medio de comunicación especial que vinculaba tanto a la Voluntad Divina como al sujeto receptor que las recibía a manera de iluminaciones mediante el don de la Gracia. LAVRIN, A.(En prensa)"Female Visionaries and Spirituality in New Spain". Susan Schoroeder y Stafford Poole, (eds.). Mexico's Transformative Church:Colonial Piety, Pogroms, and Politica Delaware: Scholarly Resources Inc. y también es fundamental el trabajo de PIKE, N. (1992) Mystic Union, An Essay in the phenomenology of Mysticism, Ithaca:Cornell University Press, pp. 28, 33, 35 y 37. 
redacción de los primeros cuadernos hagio-biográficos que hablan sobre sus discípulas. A través de estos textos se deja ver su intención de estructurar y trasmitir esquemas de comportamiento, a partir del diseño de estereotipos femeninos o modelos ejemplares a seguir, como se muestra en la selección de párrafos del cuaderno que aquí presento, escrito por el padre Miguel Godínez y que tituló "Vida y heroicas virtudes de la Madre Isabel de la Encarnación, carmelita descalza del Convento de san José y Santa Teresa de la Puebla de los Ángeles". 6

Para su estudio, en la primera parte abordaré la construcción textual del cuaderno como parte de un proceso colectivo en el que tuvieron que ver simultáneamente un confesor jesuita, una religiosa visionaria y su cronista, secretaria y amiga cercana. Como resultado de esta interacción se construyeron por un lado sistemas comunicativos específicos y por el otro, identidades diferenciadas y dependientes una de la otra. En un segundo apartado describiré brevemente las cualidades del texto reconociendo los aportes biográficos y hagio-biográficos y dentro de este último segmento centraré la atención en la sección de demonología como elemento articulador de un discurso espiritual místico y ascético, modelo vigente hasta la primera mitad del siglo XVII, y que materializó su éxito posteriormente en la edición de una "Vida" a la manera de los exempla cristianos vigentes en el viejo mundo.

${ }^{6}$ Archivo del Convento de Santa Teresa de Puebla (ACSTP). Considero a este manuscrito como uno de los documentos hagio-biográficos más tempranos (ca.1630) redactados para la Nueva España. Esta categorización parte de retomar a la narración de las leyendas ascéticas o religiosas de las vidas de los santos o de los candidatos a serlo como uno de sus componentes constructivos más importantes. Éste básicamente transmitía modelos de comportamiento en torno a la heroicidad y martirio del personaje en defensa de la fe. Desde finales del siglo XVI su producción editorial se siguió considerando importante en cuanto a su finalidad edificante, pero, al igual que otros géneros literarios se actualizó y modernizó gracias al influjo de los teólogos contrarreformistas y tridentinos. En este periodo comenzaron a utilizarse textos biográficos y espirituales como base de la nueva producción basada no ya en los atributos martirológicos o milagrosos sino que tendió a construirse resaltando la piedad y las virtudes individuales del personaje, ambas formas literarias compartían en común y de manera indisociable a la Gracia Divina como fuente de inspiración. En este mismo sentido coincidimos con la propuesta de ver a la hagiografía no como una encuesta prosoprográfica sino como un producto con función de intermediación cultural, como una "leyenda de valor teológico, idea desarrollada por VUACHEZ, A. (1989). "La hagiografia entre la crítica histórica y la dinámica narrativa". La Vie Spirituelle. Núm. 143, pp. 251-260 citado por SuIRE, E.(2001). "La sainteté”, p. 171. 


\section{LA CONSTRUCCIÓN COLECTIVA DE UN TEXTO ESPIRITUAL}

\section{Los personajes}

El padre jesuita Miguel Godínez era irlandés y su verdadero nombre fue Michael Wadding (1585-1644). La religiosidad de este linaje familiar fue manifiesta pues dos de sus hermanos pertenecieron a la misma orden y uno de ellos fue el célebre Lucas Wadding. Nuestro personaje realizó sus primeros estudios en Salamanca -España- hacia 1607, donde recibió la influencia de Francisco Suárez, cuyas teorías sobre el misticismo apreció profundamente. Ingresó como aspirante a jesuita en 1609, año en que fue enviado a la Nueva España donde realizó su noviciado en 1612 después de sobresalir en estudios humanísticos, poesía latina y teología. En 1619 tomó los votos de tercera probación y se le asignó la obra misional de Sonora y Sinaloa, territorio inhóspito de los indios tepehuanes, mayos, conicaris, tehuecos y huaveros donde desarrolló una importante labor a lo largo de varios años, dedicado a la evangelización y a la conversión de infieles. En la soledad del desierto el joven jesuita había estado en contacto con sus compañeros misioneros que, formados bajo corrientes del misticismo europeo, influirían en él decisivamente como lo manifestaría más adelante.

Se le transfirió a la ciudad de México en 1626 donde profesó de cuatro votos. A partir de entonces enseñó filosofía, teología y sagradas escrituras en el Colegio de San Ildefonso y dos años más tarde obtuvo la misma cátedra en el Colegio de San Jerónimo en Puebla donde fue rector. ${ }^{7}$ Durante sus diversas estancias en la ciudad entre 1631 y 1643 , fue confesor de dos monjas cuyas vidas ejemplares llamaron fuertemente la atención de sus contemporáneos. La Madre María de Jesús Tomellín, (1579-1637) monja profesa en el convento de La Purísima Concepción y de Isabel de la Encarnación Bonilla (1596-1633) religiosa en el monasterio de carmelitas descalzas de San José y Santa Teresa. Como director espiritual de ambas mujeres continuamente orientó teológicamente las extraordinarias manifestaciones de religiosidad que ellas expresaban a través de sus revelaciones y virtudes.

Godínez ocupó importantes cargos como rector de los colegios jesuitas de la ciudad de México entre 1631 y 1638, localizándolo en ese último año también en Guatemala. En 1641 fue propuesto como calificador del Santo Oficio de la Inquisición de la ciudad de México, puesto que ocupó en 1643 simultáneamente con el de rector del colegio de San Ildefonso de Puebla. El jesuita entabló una fuerte amistad con el virrey-obispo Juan de Palafox y Mendoza con quien

${ }^{7}$ Véase Zambrano, F. SJ (1967). Diccionario Bio-bibliográfico, de la Compañía de Jesús en México, Tomo VII, 1600-1699, México: Editorial Jus, S.A., p. 207. 
compartió algo más que puntos de vista sobre el tema de la perfección espiritual y la búsqueda de espíritus alumbrados, perfectos y proficientes en el Nuevo Mundo. Su amistad llegó a tal grado que el jesuita firmó junto con su provincial Andrés Pérez, la introducción de la primera edición del libro de Palafox, El varón de los deseos.

Entre los lectores de Palafox se encontraban también carmelitas descalzos que promovían activamente los ideales de San Juan de la Cruz. ${ }^{8}$ El más eminente representante de la orden en México fue fray Juan de Jesús María, hombre de inmensa espiritualidad que había sido Vicario Provincial y que llegó a ser consejero espiritual de obispo. ${ }^{9}$ Durante los primeros cinco años de estancia del mitrado en Puebla se dio una importante y trascendente afinidad filosófica y doctrinal con los miembros más destacados de algunas de sus órdenes religiosas como nunca antes se había visto y esta cercanía tuvo como consecuencias variadas expresiones culturales, una de las más importantes, aunque menos conocida, fue la promoción de la escritura conventual. ${ }^{10}$

Reforzando esta afinidad teológica, el jesuita ordenó la redacción de los primeros cuadernos hagiográficos sobre las dos notables religiosas. Los referentes a María de Jesús fueron utilizados para fortalecer la iniciativa de Palafox al

8 El texto más utilizado de este autor es, (1984) Subida del Monte Carmelo. Noche Oscura. Cántico Espiritual. Llama de Amor Viva. México: Editorial Porrúa, S.A.

${ }^{9}$ TronCARelli, F.(1999). Palafox y la cultura político religiosa del siglo XVII". El mismo autor sostiene la gran influencia que sobre las posiciones políticas de Palafox ejerció el irlandés William Lamport también conocido como Guillén Lombardo, y que le costaron su deposición como obispo de Puebla. Véase La Spada e la Croce Guillén Lombardo e l'Inquizicione en México. Roma: Salermo Editorie.

${ }^{10}$ Coincidencia compartida con el desarrollo de la mística moderna en España a raíz de la primera edición de las obras de SANTA Teresa de Jesús véase el Libro de la Vida. (1995). Barcelona: Editorial Altaya, el tema biográfico es descrito en las pp. 119 a 140. Se debe reconocer que la obra de la Santa fue un modelo de inspiración tanto en Europa como en Hispanoamérica, Como ejemplos de éste proceso en España pueden consultarse; Howe, E. (2004). The Visionary Life of Madre Ana de San Agustín. Suffolk:Tamesis, Poutrin, I. (1995). Le voile et la plume. Autobiographie et sainteté dans L'Éspagne moderne. Madrid: Casa de Velásquez, Que muestra a través de la escritura de esta religiosa que fue discípula de Santa Teresa, los variados rasgos de similitud entre ambas. Para los casos Hispanoamericanos pueden verse: McKNIGHT, K.(2000). The Mystic of Tunja; The Writings of Madre Castillo, 1671-1742. Amherst: University Press, Iturburu,F. (2001). (Auto) biografia y misticismo en la Colonia: la relación escrita por madre Josefa de la Providencia sobre madre Antonia Lucia Mandonado. New Orleans: University Press of the South ; Ramos Medina, M. (1997). Misticas y descalzas. México: Condumex, Véase también, ARMACANQUI-TiPACTI, E.J. (1999) Sor María Manuela de Santa Ana: una teresiana peruana. Cuzco: Centro de estudios Regionales Andinos "Bartolomé de Las Casas". 
comenzar el proceso de beatificación de la monja concepcionista sirviendo de argumentación justificativa ante el Vaticano de la primera exhumación el cadáver de la religiosa. ${ }^{11}$ La amistad y el trabajo conjunto entre ambos sacerdotes le causó al religioso de la Compañía ciertas tensiones dentro de su orden al desafiar a algunos de sus superiores que no sentían simpatía por la política del nuevo obispo que aspiraba a suprimir los privilegios de toda las órdenes. La controversial participación política del obispo y la muerte de Godínez en 1644 contribuyeron que la "Causa del Lirio de Puebla" fuera interrumpida en la Sagrada Congregación de Ritos en la ciudad papal. ${ }^{12}$

De manera paralela y con intereses semejantes Miguel Godínez redactó un cuaderno donde narra la vida, tentaciones y virtudes de Isabel de la Encarnación, la religiosa carmelita descalza contemporánea de María de Jesús. Es sobre este documento inédito sobre el que centraremos nuestra atención. Se debe destacar que no fue casualidad que tan notable jesuita asociado con una declarada tendencia hacia la mística, ${ }^{13}$ fuera director espiritual de estas dos monjas poblanas, además de influir sobre las respectivas secretarias de ambas Agustina de Santa Teresa y Francisca de la Natividad ${ }^{14}$ respectivamente.

${ }^{11}$ La escritora de estos primeros apuntes sobre María de Jesús, fue Agustina de Santa Teresa, compañera de María de Jesús (1619-1668). Libro de Profesiones, Archivo del Convento de la Concepción de Puebla. ACCP Hasta el momento estos cuadernos no han sido localizados, su referencia se ha tomado de las múltiples ediciones de su vida. DRAGO M. (2000). "Sor María de Jesús Tomellín (1579-1637) Concepcionista poblana: la construcción fallida de una santa", tesis de PhD, University of New York.

12 Durante la estancia de este mitrado se editó la primera biografía de María de Jesús cuando apenas contaba con 9 años de fallecida. Posiblemente la iniciativa de Palafox sobre esta monja obedeció al interés de hacer coincidir la terminación de la magnífica catedral poblana, su dedicación a la Purísima Concepción de María y la beatificación de una religiosa de la misma orden representante del grupo criollo de la América Septentrional que tanto le quiso. Al respecto puede verse LORETO L., R. (1998). "Las pruebas del milagro en el proceso de beatificación de la Madre María de Jesús en los siglo XVIII y XIX". Manuel Ramos Medina, (comp.). Historia de la Iglesia en el Siglo XIX. México: El Colegio de México, El Colegio de Michoacán, Instituto Mora, UAM-IZTAPALAPA, CONDUMEX, pp. 351-368.

${ }^{13}$ La mística es la parte de la ciencia espiritual que tiene por objeto propio la teoría y la práctica de la vida contemplativa, desde la noche de los sentidos hasta el matrimonio espiritual mientras que la ascética tiene por objeto la teoría y la práctica de la perfección cristiana desde sus comienzos hasta los umbrales de la contemplación infusa. TANQuerey. (1930). Compendio de Teología, Ascética y Mística: Madrid: Sociedad de San Juan Evangelista, p.7.

${ }^{14}$ Las crónicas citan la existencia de cuadernos hagio-biográficos sobre la madre Isabel de la Encarnación redactados por su priora Melchora de la Asunción (Monja asturiana fundadora del monasterio de Santa Teresa de Puebla, que profesó en 1606 y falleció en 1631 hasta el momento desconocidos) y por su compañera de celda Francisca de la Natividad quien profesó en 1608 y murió 
Aunque el padre Godínez fue trasladado a la ciudad de México -donde fue rector de San Ildefonso y prefecto de estudios del colegio máximo de la Compañía de Jesús- durante más de diez años continuó su relación epistolar en la que Agustina y Francisca, como intermediarias, eran sus corresponsales. ${ }^{15}$

Como producto de su madura formación teológica y doctrinal y de manera casi paralela al trabajo de dirección espiritual con las religiosa poblanas, Miguel Godínez escribió un tratado: Práctica de la Theología Mistica ${ }^{16}$ que estuvo en total coincidencia con las posiciones tridentinas del obispo, inspirado en las propuestas del misticismo contrarreformista de San Juan de la Cruz, Santa Teresa de Ávila, Tauless y Ruysbroeck. En opinión de Pilar Gonzalbo, la exaltación espiritual del padre Godínez resultaba en ocasiones excesiva para la disciplina jesuítica, razón por la cual no vio impresa en vida su magna obra dado que había conseguido inquietar a los inquisidores novohispanos. ${ }^{17}$

\section{Los métodos: oír, ver y escribir.}

Los jesuitas emplearon métodos originales que resultaron eficaces para el adoctrinamiento de amplios y diversos estratos de la población, destacándose los dedicados a la instrucción y catequesis infantil. Para los adultos establecieron cursos de teología moral que llamaban "cátedras de casos", con el objeto de instruir a clérigos seculares sobre la comprensión de problemas de conciencia. ${ }^{18}$ También editaron manuales de confesión orientados a facilitar la conversión de adultos y

en 1658. (ACSTP), Libro de Profesiones. Un estudio sobre ésta última muestra como la redacción del texto hagiográfico continuamente utilizaba estructuras narrativas del biográfico, al respecto puede consultarse LORETO L., R. (2002). "Escrito por ella misma. Vida de la madre Francisca de la natividad, 1630". En LAVRIN, A.y R. LORETO L., (eds). Monjas y betas. La escritura femenina en la espiritualidad barroca Novohispana. Siglos XVII-XIX, México, Universidad de las Américas,Puebla/Archivo General de la Nación, pp. 24-66.

${ }^{15}$ Sobre esta idea véase GonZalbo A. P. (2002) Reseña a Asunción Lavrin y Rosalva Loreto L. (eds.). Monjas y beatas...en Estudios de Historia Novohispana, Instituto de Investigaciones Históricas, UNAM, México, Núm. 27, julio-diciembre, pp.243-249.

16 Godinez. M. Práctica de la Teología Mística. La primera edición se hizo en 1681, facturándose otras cuatro en castellano durante el siglo XVIII. También escribió El gobierno religioso (2 volúmenes) y Horologii descrriptio, hexametris latinus.

${ }^{17}$ GonZalbo, A. P.(2002). "Reseña”, págs. 243-249.

18 Gonzalbo, A.P.(2001). "La educación jesuita”.Colegios Jesuitas. México: Editorial Artes de México, revista-libro, Núm.58,p.56. 
paganos. ${ }^{19}$ Estos textos se redactaron y publicaron en la Nueva España y se utilizaron en combinación y como complemento del modelo religioso propuesto por el fundador de la Compañía de Jesús, San Ignacio de Loyola, cuyo programa y método se plasmó en los Ejercicios Espirituales. ${ }^{20}$ A esta profusa producción editorial se añadió la eclosión plástica y estética característica del barroco, movimiento intelectual que activó ricas y variadas devociones que permitieron orientar a las almas de acuerdo a las necesidades de cada grupo de fieles. ${ }^{21}$

Las cualidades pedagógicas y metodológicas de estos textos se reforzaron metódicamente mediante la confesión individual, que se conformó como el instrumento privilegiado de comunicación individual desarrollado por la espiritualidad barroca y fue compatible con los modelos doctrinales de las otras órdenes mendicantes. ${ }^{22} \mathrm{Al}$ confesor le correspondió transmitir un sistema de signos para organizar la función de los sentidos, preconizando el uso de las referencias sensoriales y afectivas, generando imágenes mentales como vía de elevación y

19 Brading, D. (2001). "La patria criolla", p. 62, cita el caso del padre Antonio del Rincón descendiente de la casa real de Texcoco quien además de enseñar latín en el Colegio de San Jerónimo de Puebla, también ejercía su ministerio entre los indios de la ciudad predicando y confesando en "mexicano". Este religioso publicó en 1595 Arte mexicana, una gramática y guía para sacerdotes dedicados a atender a los indígenas.

${ }^{20}$ Se pueden considerar entre los libros más re- editados en la Nueva España a partir del último cuarto del siglo XVI. San Ignacio de Loyola. Ejercicios Espirituales. México: Ediciones Paulinas, 2001. Siguiendo este modelo los jesuitas escribieron otros que se pueden considerar complementarios, ya para el siglo XVIII fueron empleados con asiduidad los del padre RodRíGUEZ, A. (1727). Exercicio de Perfección y virtudes cristianas. Madrid: Francisco del Hierro, Impresor, 3 tomos. En este sentido llama la atención la especial dedicación de los jesuitas hacia la orientación espiritual exclusivamente de las monjas, el texto más localizado en bibliotecas conventuales tanto españolas como novohispanas fue; La religiosa en Soledad, obra en que se expone a las religiosas el modo de emplearse con fruto en los ejercicios espirituales de San Ignacio de Loyola (...). Compuesta en Italiano por el padre PINAMONTI, J.P. SJ (1733). Traducida en español por el padre Martín Pérez Culla, De la misma Compañia. Madrid: Antonio Sanz, Impresor de libros. Con la misma orientación edificante se publicaron también sermones dedicados a monjas ejemplares y discursos morales, al respecto véase Discursos escriturales y morales para útil y provechoso entretenimiento de las religiosas. Escritos en Italiano por el padre CALINO, C. SJ. (1794). Traducidos al español por el padre Domingo Ascarza de la misma Compañía. Madrid: Imprenta de Joseph Doblado.

${ }^{21}$ San Ignacio dentro de las reglas para "sentir con la iglesia" exhortaba a la veneración de reliquias de santos e imágenes piadosas, asistencia a misa y si bien rara vez promovían nuevas devociones, aceptaba las revelaciones privadas. BRADING, D.(2001). "La patria criolla", p.61.

22 RANF,P., A Woman's Way, pP.107-157 . Sostiene que durante el siglo XVI las reformas religiosas afectaron de manera directa algunos aspectos de las prácticas cristianas y uno de ellos fue la confesión sacramental que en adelante atribuiría tanto el confesor como del director espiritual; la preservación del orden social y la rectificación del orden moral interior. 
trascendencia. Las religiosas escuchaban e imaginaban y mediante la percepción del mensaje conseguían pasar a la contemplación. Mediante esta experiencia se lograba inflamar al individuo con la más alta de las pasiones, la "contemplación para el amor". ${ }^{23}$

El director espiritual, oralmente y mediante descripciones-referenciales en torno a la Pasión de Cristo, lograba que cada monja generara su propia "composición del lugar" $^{24}$ y fue a partir de estos recursos imaginarios que se potencializaron las capacidades espirituales y mnemotécnicas de cada religiosa. Una vez que estas características eran reconocidas por parte del confesor se establecía una relación especial donde la voluntad la palabra oral y la escritura, se conformaron como un sistema de comunicación que involucraba a los tres. ${ }^{25}$

Los escenarios generados para la producción de imágenes, requerían para su explicación, complementarse a través de composiciones gestuales de comportamientos y actitudes en consonancia con la Imitatio Christi. Cada religiosa le daba a su propia experiencia una dimensión que implicaba avances y retrocesos y que gracias a la confesión desplegaba posibilidades alternativas y condiciones de desplazamiento. Su expresión dependió del uso del lenguaje metafórico, moralizante y alegórico. ${ }^{26}$

23 Alfaro, A. (2004). "Las formas del espíritu". Arte y espiritualidad jesuitas. México: Artes de México, Revista-libro, Núm. 70, p.6.

24 En diversos estudios se ha reconocido a "la composición del lugar" como parte fundamental del método ignaciano basado en la introspección piadosa que motiva el uso de la imaginación que en combinación con la orientación en el uso de los sentidos y los afectos, genera la construcción de imágenes mentales asociadas con la pasión de Cristo. Este método fue compartido también por la mística teresiana en la construcción de la espiritualidad barroca. Al respecto véase CHINCHILLA PAwling, P. (2001). "La composición del lugar, de la Imaginación a la memoria" Historia y Grafía, México, UIA, Núm.16, pp.15 -43 y PfEIFFER, H. SJ. (2004) "Los jesuitas arte y espiritualidad". Colegios jesuitas, México: Artes de México, Revista-libro, Núm. 58, pp., 47-51.

25

Dentro de la retórica contrarreformista, la voluntad es el principio o fundamento, es la disposición de vida para cambiar o modificar la propia siguiendo un modelo: Cristo. Se fundamenta así el cristocentrismo como un componente esencial de la mística moderna que es compartida por sus principales representantes españoles. Véase BARRIOS,A.(2002). Introducción a la lectura de Santa Teresa, Madrid: editorial Espiritualidad, Segunda Edición, pp. 216 y 217.

${ }^{26}$ Al respecto puede consultarse el ya clásico trabajo de CERTEAU, M. (1992) JS. The Mystic Fable. Chicago and London: The University of Chicago Press, y del mismo autor, (2004). "El espacio del deseo" en Arte y espiritualidad jesuitas. México: Artes de México, Revista-libro, Núm. 70, pp $39-47$. 
Los jesuitas, al igual que los mendicantes, coincidieron en conformar una retórica del cuerpo y de sus pasiones utilizando en su lógica la humanización de Cristo como parte de un esquema sólido y funcional contra cualquier herejía. ${ }^{27} \mathrm{La}$ carnalidad del hijo de Dios sirvió como devoción metódica y personal, su imitación exigía representaciones visuales y emotivas a través de su ejemplo divino: era la presencia carnal del sufrimiento. La monja mediante la voluntad y la orientación de su padre espiritual organizaba sus conductas afectivas, articulando cambios de comportamiento a través de prácticas concretas como el ayuno, las disciplinas, la penitencia y la mortificación.

Las prácticas ascéticas se combinaron siempre con una metodología de sustento teológico mediante la oración, la meditación y la contemplación. Las visionarias convertían las manifestaciones, propias de la iluminación individual, como los raptos y los éxtasis, en un instrumento de la mística siguiendo las trayectorias señaladas por la teología. ${ }^{28}$ Reconocían sus afectos y mediante la humillación personal limpiaban su alma (vía purgativa), ordenaban los sentidos para sentir a Dios (vía iluminativa), para hallar la voluntad de Dios (vía unitiva). Se transformaba el "trabajo" y el sufrimiento en ofrenda para hacer del cuerpo un instrumento de comunicación entre el cielo y la tierra. ${ }^{29}$

A través de la retórica barroca se orientó metodológicamente la dimensión sensible y emocional de la experiencia interior de las religiosas, contribuyendo a modelar los comportamientos a través del manejo de los sentidos, los afectos y el seguimiento de las virtudes. En algunos casos y con el objeto de mantener una

27 En el sistema simbólico del cristianismo temprano el concepto de la encarnación y humanización de Cristo es una parte fundamental para explicar la unión corporal de la carne con la divinidad a partir de una relación posible entre el cuerpo y alma. En el siglo XII este concepto sirvió como soporte explicativo en la comprensión de Dios representado como un hombre, al cual había que imitar, lo que permitía un hallazgo dentro de uno mismo, partiendo de una naturaleza humana hecha a imagen de Dios que era semejante para todos los seres humanos. Bynum, C. W. (1984). Jesus as Mother. Studies in the Spirituality of the High Middle Ages. Los Angeles: University Press, 1984, pp. 87-90 citado por DURAN N. (2003). "La construcción de la subjetividad en las hagiografías, un caso: Sebastián de Aparicio".Camino a la Santidad, Siglos XVI-XX, en Manuel Ramos Medina, (coord.). México: Centro de Estudios de Historia de México, Condumex, p.173. Sobre este tema en relación particular con la mística puede consultarse a UNDERHILL, E. (1990).Mysticism. New York: Doubleday.

${ }^{28}$ Estas tres vías o caminos para alcanzar la unión mística fueron reconocidas y explicadas profusamente en la Práctica de la Theología del padre Godínez en el siglo XVII. Trabajando con otros místicos se ha planteado la posibilidad de reconocer variados niveles en la búsqueda del camino de perfección. Véase UnderhiLl, E.(1990). Mysticism, pp. 176-197.

${ }^{29}$ Alfaro, A. (2004). "Las formas del espíritu”, p. 6. 
observación secuencial y cotidiana, los sacerdotes ordenaron la escritura de cartas y diarios espirituales que les permitían valorar el avance espiritual de su pupila, lo orientaban y lo censuraban según el caso.

Gracias a la aplicación cotidiana de este conjunto de ejercicios y prácticas confesionales ellos pudieron identificar dentro de los conventos a las monjas depositarias de una gracia divina que las destacaba como espíritus privilegiados. Reconocían en éstos sus variados grados de espiritualidad, centraban su orientación sobre los caminos que ellas debían seguir para conocer el amor de Dios, acompañándolas muy de cerca en su propia búsqueda de iluminación interior. En estos casos la escritura de cuadernos hagio-biográficos ${ }^{30}$ se convirtió en el instrumento de soporte espiritual de la mística, que permitió la transferencia de la oralidad a la práctica de lo escrito.

En cualquiera de los casos, esta redacción estableció una condición que debe ser valorada en el proceso de la alfabetización, pues esta práctica permitió trasferencias múltiples encaminadas a la consolidación de distintos sujetos individuales. ${ }^{31} \mathrm{La}$ monja visionaria se construía a sí misma viéndose como criatura frente al Creador, experimentando el camino de las virtudes, la oración y la contemplación. En la monja- secretaria se proyectarían, a través de la observación de su compañera y la composición narrativa, sus propias capacidades de reconocerse como escritora. Para el confesor se abría la posibilidad de identificarse a partir de oír, ver, entender y escribir las experiencias de la visionaria asumiéndose él mismo como vehículo de Dios. ${ }^{32}$ Así Agustina, Francisca o Melchora realizaron una escritura en las que se plasmó de manera sencilla todo el accionar gestual, discursivo, sin diferenciaciones cronológicas de Isabel. Más tarde el padre Godínez procedió a la contextualización biográfica de las experiencias narradas, clasificó los párrafos en función de los personajes y los temas, para finalmente asociarlos con el esquema hagiográfico y místico según las virtudes sobresalientes de la religiosa en cuestión.

${ }^{30}$ Véase nota 6 de este capítulo.

${ }^{31}$ Se ha considerado la escritura hagiográfica como una de las tecnologías privilegiadas de la Edad Media para construir la identidad y una de sus estructuras más importantes fue el binomio tentación/culpa. Esta tradición fue continuada en la Nueva España. Véase DurÁN,N. (2003)."La construcción de la subjetividad", pp.167 yss . En este sentido los textos espirituales femeninos también pueden considerarse dentro de las tecnologías de la modernidad.

32 Esta tendencia proviene de un impulso renacentista que buscaba ampliar y fortalecer los espacios de autonomía del individuo permitiendo la exploración de territorios interiores y de difícil acceso, situados más allá de la conciencia racional. Alfaro,A.(2004). "Las formas del Espíritu", p.6. 


\section{LAS CUALIDADADES DEL TEXTO.}

\section{"De las varias figuras en que se le aparecían los demonios"}

La memoria del barroco fue dotada -gracias al antropocentrismo renacentistade sangre y piel, pasiones y afectos. Los argumentos de la teología de las imágenes sagradas resultaban convergentes con un nuevo programa estético, tanto plástico como narrativo, donde el cuerpo podía resumir su carácter de vehículo de trascendencia y su experiencia se podía narrar biográfica, hagiográfica, y gráficamente. Es en este contexto donde se inscribe la escritura del cuaderno del Padre Godínez.

El documento está compuesto por 63 folios dobles (126 sencillos). Quedó estructurado de manera secuencial hasta el capítulo 22 (50 folios) a partir del cual se inserta la repetición numérica de los capítulos 14, 15 y 16 con una anotación final que señala el deseo del autor de colocar posteriormente estos últimos capítulos en su respectivo lugar, hecho que, por cierto, no se realizó. Cabe hacer la aclaración que, tanto estos nuevos títulos añadidos, como su contenido, son diferentes del resto del manuscrito, lo cual permite un enriquecimiento del cuaderno en su conjunto.

Se pueden distinguir dos tendencias narrativas a lo largo del manuscrito. La primera se adecua al género biográfico ${ }^{33}$ desarrollado en los capítulos 1 al 9 . En seguida hace su aparición el personaje elegido para el desarrollo de los capítulos siguientes: el demonio, cuya trama se inserta más que en un género literario, en una corriente de teología mística y ascética cristianas ligadas a la hagiografía ${ }^{34}$ y que permite un doble desarrollo. El primero abarca propiamente el despliegue activo del citado personaje y lo refiere a los capítulos del 10 al 16, reincidiendo temáticamente en los numerados con el 22 y los de nueva factura 14 y 15 . En esta sección es notable la influencia metodológica de los jesuitas. La otra sección incluye el desarrollo de los comportamientos ascéticos y místicos propuestos por la corriente carmelitana que se muestran en los capítulos del 17 al 21 y el 13 y el 16

33 Historia circunstanciada de la vida y hechos de algún particular. Colección de vidas particulares, más o menos públicas descriptivamente individualizadas. Nuevo diccionario de la lengua castellana. París: Librería Bouret e Hijo, 1877, p.184.

${ }^{34}$ Ciencia que trata de las leyendas ascéticas o religiosas, de las vidas de los santos o sus escritos. Dáse este nombre principalmente al tratado o escrito sobre aquella parte del Antiguo testamento que no corresponde a Moisés ni a los profetas; o la obra o discurso o tratado hecho con la asistencia del Espíritu Santo. Ibidem, p. 656. 
que fueron añadidos. Todos cohesionados bajo el esquema hagiográfico propuesto por el padre Godínez. El siguiente cuadro da muestra de esta relación:

División del capitulado del texto de la Vida y Heroicas Virtudes de la Madre Isabel de la Encarnación

\begin{tabular}{|c|c|c|c|}
\hline & Biografico & Demonologico & Ascetico-Mistico \\
\hline numero de capitulos & 1 a $9=9$ & $\begin{array}{l}10 \text { a } 16=6 \text { más el } 22 \\
\text { y el } 14^{*} \text { y } 15^{*}=9\end{array}$ & $\begin{array}{l}17 \text { a } 21=5 \text { más el } \\
13^{*} \text { y el } 16^{*}=7\end{array}$ \\
\hline numero de folios & 1 a $20=20$ & $\begin{array}{l}20 \mathrm{v} \text { a } 32 \mathrm{v} \text { y } * * \text { de } 49 \\
\text { a } 58 \mathrm{v}=22\end{array}$ & $\begin{array}{l}33 \text { a } 48 v \text { y } * * \text { de } 61 \text { a } \\
62 \mathrm{v} \text { y de } 59 \text { a } 60 v= \\
21\end{array}$ \\
\hline
\end{tabular}

*Se refiere a los capítulos propuestos para corrección y añadidura redactados en la última parte del manuscrito. ${ }^{* *}$ Se incluye la paginación de los capítulos repetidos

En este capítulo hablaremos muy brevemente del desarrollo del primero y del tercer modelo para centrarnos en cambio en la segunda parte, en el aporte demonológico. Consideramos a éste de particular originalidad pues fue redactado utilizando al personaje satánico en facetas poco conocidas para el ámbito novohipano además, por supuesto, de ser usado para instrumentar el camino de prueba y purificación, tránsito necesario en la búsqueda de la vida de perfección. Otra característica del texto es su función articuladora, pues su escritura fue una condición para el desarrollo de toda la tercera parte referente a la mística y ascética, que como experiencia individual era factible de ser alcanzada por algunas mujeres en el Nuevo Mundo. Godínez retomaría y desarrollaría esta propuesta formalmente en el modelo moral plasmado en su Práctica de la Theología Mística y que será objeto de otro estudio.

\section{El aporte biográfico}

Entre los siglos XI y XIII cobraron importancia en la cultura occidental la mística y la ascética cristianas y su modelo de difusión por excelencia fue la hagiografía. Más tarde, entre los siglos XVI y XVII, estos conceptos cobraron una importancia inusitada en el marco de las doctrinas contrarreformistas y fueron retomados y desarrollados como modelos en los ya conocidos escritos de los místicos españoles cuyos textos fueron sancionados y difundidos por las reformas emanadas del Concilio de Trento (1545-1563). Su influencia se dejó ver en la producción de los escritos producidos bajo el ámbito de la espiritualidad barroca.

Estos modelos de escritura surgieron paralelamente al desarrollo de una teología escolástica modernizada por Trento y estuvieron asociados a nuevas formas de 
devoción que por un lado rescataban la búsqueda de las raíces primitivas de la iglesia y por otro se adaptaban a la experiencia y necesidades individuales de hombres y mujeres. Fue precisamente esta adaptación a la retórica barroca ${ }^{35}$ lo que permitió incluir en estas nuevas corrientes a sectores hasta el momento marginados del discurso ortodoxo cristiano: las mujeres. ${ }^{36}$

Podemos considerar que en la Nueva España, Miguel Godínez fue uno de los primeros religiosos en retomar los causes de esta escritura femenina con el objetivo de promover y hacer pública la vida ejemplar de las religiosas. A partir de la orientación y la aplicación de un moderno esquema doctrinal místico era posible proponer y desarrollar con las religiosas esquemas de civilidad y comportamientos en torno al seguimiento de las virtudes. De manera importante estos documentos servían para convalidar la observancia de la ortodoxia cristiana de las experiencias sobrenaturales de las religiosas.

En la obra del padre Godínez la sección encaminada a describir la vida y virtudes de Isabel comienza, como todas las del estilo hagiográfico de la época, narrando la infancia y las dificultades a las que se vio sometida cuando aspiraba a entrar al convento. ${ }^{37}$ Una vez logrado el ingreso se describe el continuo batallar y las duras pruebas que experimentaba en el noviciado y el jovenado, pruebas que tenían que ver con la constancia de la vocación, pero sobre todo con el desarrollo de ciertas conductas y virtudes como la humildad, la paciencia y la obediencia. En el caso de Isabel las enfermedades fueron parte de estas pruebas, y junto con las mortificaciones, penitencias y ayunos fueron su salvoconducto corporal para estar en contacto íntimo con Dios. Estos sufrimientos, a los que sumó el ejercicio de la virtud de la prudencia, le permitieron soportar a los confesores incomprensivos cuando fue sometida a exorcismos.

\section{El aporte demonológico}

La segunda parte del texto hace alusión a la constante participación del demonio. Este personaje formó parte del imaginario cultural y religioso aceptado

${ }^{35}$ La retórica textualmente se asocia con el arte de la oratoria, fecundo en imágenes, figuras o metáforas sublimes. Podemos añadir que en este caso, fueron formas y maneras de expresión asociadas con el discurso teológico y todo su bagaje cultural desarrollado entre los siglos XVI y el XVIII.

36 Sobre bibliografía específica de esta temática puede consultarse; LAVRIN,A. y LORETO,R. (2002). Monjas y Beatas, Introducción, pp.5-23. 149 .

${ }^{37}$ Véase el ejemplo de SANTA Teresa de Jesús. (1995). Libro de la vida, Capítulos I-V, pp.,107- 
durante los siglos XVI y XVII. Isabel de la Encarnación sostuvo una batalla constante con él bajo varias facetas, una de ellas y la más destacada por Godínez, fue la de la animalidad. En esta arena, el objeto de disputa central fue su propio cuerpo, su control, el mantenimiento de la pureza y la castidad, y la construcción de una gestualidad femenina, constituyeron los triunfos espirituales de las monjas y de su director espiritual.

Asociada a la riqueza del material documental se encuentra una característica fundamental e invariable, el texto escrito por el religioso nos habla de hechos maravillosos que fueron el fundamento de la construcción del imaginario conventual poblano. ${ }^{38} \mathrm{El} \mathrm{mecanismo} \mathrm{por} \mathrm{medio} \mathrm{del} \mathrm{cual} \mathrm{éste} \mathrm{se} \mathrm{reprodujo,} \mathrm{se} \mathrm{basó}$ en las apariciones, las visiones y las revelaciones siempre bajo la contextualización de reconocerlos como hechos sobrenaturales. Durante estas experiencias Isabel se enfrentó a la acción de seres y objetos de naturaleza demoníaca y celestial, siendo Dios -según la construcción del padre Godínez- el único autor de tales confrontaciones.

Estas revelaciones fueron consideradas signos de gracia sobre el alma humana y aceptadas por la Santa Sede una vez que los testimonios habían sido debidamente examinados y avalados por una autoridad religiosa en este caso, el jesuita confesor. En las argumentaciones hagiográficas y teológicas de Godínez el significado y la procedencia de las visiones fueron consideradas de manera especial. Se analizaron detalladamente con la intención de diferenciar las manifestaciones de iluminismo, a que estaba sujeta la carmelita descalza, de las provenientes de las falsas beatas también conocidas como alumbradas, contemporáneas de Isabel de la Encarnación. $^{39}$

${ }^{38} \mathrm{Al}$ respecto puede verse LORETO R. (2002). "The Devil, Women, and the Body in SeventeenthCentury Puebla Convents". The Americas, Vol. 59, Núm.2, October, pp. 181-199.

${ }^{39}$ Los casos de las alumbradismo o falsa beatitud femenina han sido trabajados profusamente en los archivos inquisitoriales, véanse: Bravo D. (1984). Ana Rodríguez de Castro y Aramburu, ilusa, afectadora de santos, falsos milagros y revelaciones divinas. Proceso Inquisitorial en la Nueva España (siglos XVIII y XIX), México: Instituto Nacional de Bellas Artes/SEP Cultura, Universidad Autónoma Metropolitana; HolleR,J.(1993). "I, Elena de la Cruz: Heresy and gender in México City, 1568". Journal of Canadian Historical Association, Núm.4, pp. 143-60; (1997). "More Sins than the Queen of England: Marina de San Miguel Before the Mexican Inquisition" in Mary Giles (ed). Women in the Inquisition: Spain and the New World. Baltimore: Johns Hopkins University Press, pp. 209-228; (2000). "The Spiritual and Physical Ecstasies of a Sixteenth-Century, Beata: Marina de San Miguel Confesses Before the Mexican Inquisition (México, 1598)". Richard Boyer and Geoffrey Spurling. (Eds). Colonial Lives: Documents on Latin American History, 1550-1850. New York: Oxford University Press, pp. 77-100; RuBial, A. (2002). "Josefa de san Luis Beltrán, la cordera de 
A principios del siglo XVII la iglesia católica promovió la edición de tratados morales y doctrinales ${ }^{40}$ que pudieran arrojar luz para diferenciar las conductas místicas y para eso había que tipificarlas canónicamente según su naturaleza, ${ }^{41}$ definiéndolas en relación con las experiencias espirituales y con los sentidos del alma y sus sensaciones. ${ }^{42}$ En este sentido Godínez no las consideraba un requisito del misticismo, pero como buen jesuita estaba abierto a su comprensión, como lo muestra en el señalamiento siguiente:

... las revelaciones no son partes esenciales ni integrantes de la vida espiritual, como lo notó muy bien San Buenaventura, por que como no son actos de ninguna virtud, no son de suyo meritorias (...) sino un ornamento accidental de la vida espiritual. ${ }^{43}$

Las revelaciones y las visiones de Isabel fueron reconocidas después de darles un fundamento doctrinal, como un mecanismo válido de comunicación entre Dios y la monja. ${ }^{44} \mathrm{Su}$ objetivo lo reorientó continuamente el director espiritual para

Dios: escritura, moralidad y gestualidad de una visionaria del siglo XVII Novohispano. 1654". Lavrin, A. y R, LORETO. (Eds.) Monjas y beatas, pp.161-204.

${ }^{40}$ Para aclarar el papel del misticismo dentro del conjunto doctrinal de la Iglesia católica puede verse, Pelikan, J. (1985). The Christian Tradition.A History of the Development of Doctrine Reformation of Church and Dogma (1300-1700), Vol.4. Chicago: The University of Chicago Press, pp.63-68.

${ }^{41}$ Para Godínez la revelación, los raptos y las visiones eran manifestaciones secundarias en el ejercicio de las virtudes, señaló, sin embargo, como requisito necesario parte del maestro de espíritu el saber reconocer la existencia de dos tipos; una intelectual y una sensitiva con el fin de identificar cualquier malabar del demonio. GodínEZ, M. (1761). Práctica de la Theología, pp.349-379 y UNDERHILl, E. (1990). Mysticism, cap V, pp. 95-124.

42 Tratando de definir la naturaleza de las visiones Godínez recomendaba el reconocimiento de las causas y consecuencias que acompañaban a la unión mística; éxtasis, arrobos y los fluctuantes movimientos del alma que incluyeron momentos de depresión o melancolía; las sequedades, noches obscuras, desamparos y la pasividad que debía acompañar las locuciones; las virtudes y la devoción. GodíneZ, M. (1761), Práctica de la Theología , pp. 101- 131. Al respecto debe verse obligadamente a SAn Juan de la Cruz, Subida del Monte Carmelo.(1984)., pp. 236 y PIKE,N.(1992). Mystic Union, p. 42; Weissner.W.(1992) S.J., M.D., Ignatius of Loyola.The Psychology of a Saint. New Haven: Yale University Press, pp.279-345. Este autor señala que a partir de la experiencia mística del santo se consideraron a las visiones como complemento de las manifestaciones místicas. Experiencia compartida y avalada mutuamente por la corriente carmelitana.

43 GODINEZ M.,Ca. 1630, f.44.

${ }^{44}$ Uno de los principales argumentos que abrieron esta posibilidad de experiencia de vida para las monjas se concretó a partir de la edición de la obra de SANTA Teresa de Jesús. (1995). Libro de la vida, concretamente el capítulo XX relativo a la luz del alma llamada éxtasis, pp. 263 y ss., y el 
aprovechar las enseñanzas que provenían de los mensajes sagrados. Además sirvieron para reafirmar los métodos de devoción jesuitas al integrarse de alguna manera al modelo teológico de castigo-gracia.

Los recursos mediante los cuales se manifestó lo maravilloso hagiográfico de las revelaciones fueron los sueños, la metamorfosis, las alucinaciones y las sensaciones. Estas manifestaciones sobrenaturales fueron categorizadas y cargadas de contenidos simbólicos y culturales y formaron parte importante del catolicismo barroco novohispano. Dios, como autor de las apariciones y de los milagros, ejercía el control y reglamentaba todas las acciones de las religiosas. Gracias al empleo de un sistema simbólico, se dotó de funciones específicas a cada personaje del imaginario conventual. En las apariciones intervenían, además de Cristo y la Virgen, las almas del purgatorio y las milicias angélicas mediadoras entre las monjas, el diablo y los demonios.

Una vez que la información sobre las visiones había sido escrita por la biógrafa, en este caso Francisca de la Natividad y reinterpretada y re escrita por el confesor, pasaba formar parte de un sistema de categorías que se integraba temáticamente como lo muestra la sección del documento aquí analizado, el capítulo 10 "De las varias figuras en que se le aparecian los demonios y de los innumerables tormentos que le causaban"45 y que fue utilizado por Godínez para dar inicio a la segunda parte del manuscrito.

Dios se valía de la obsesión demoníaca como mecanismo para purificar las almas escogidas y prepararlas para la unión mística. Esta última parte fue desarrollada por Godínez en ciertos capítulos de la tercera parte. En este sentido el demonio formaba parte del plan divino pues los tormentos por él aplicados

capítulo XXVIII, en el cuál describe sus visiones, 335 y ss. Este texto se debe considerar como una de las fuentes más importantes en la conformación del esquema de la retórica oral y corporal de las visionarias en Hispanoamérica. Ahlgren, G. T.W. (1996) Teresa of Avila and the Politics of Sanctity. Ithaca and London: Cornell University Press, pp. 83. Plantea que los contemporáneos de Teresa dieron evidencias de sus poderes espirituales como la levitación, éxtasis y profecías y ha propuesto la clara interdependencia existente entre las visionarias y la tradición mística pág.112. En el mismo sentido se ha utilizado la figura de la Santa como muestra de la continuidad de la tradición medieval que avala las visiones como evidencia espiritual. En el mismo sentido puede verse también WEBER, A. (1990). Teresa of Ávila and the Rhetoric of Feminity. Princeton: Princeton University Press.

${ }^{45}$ GodínEZ, M. Ca.1630, f.20. 
"parecían aumentar en proporción al grado de virtud y de paciencia con que se toleraban". ${ }^{46}$

El desarrollo de los conceptos sobre el diablo y los demonios formó parte de un largo proceso que incluyó la transformación de lo cultural mágico a lo sobrenatural, durante el siglo XVI y el primer tercio del siglo XVII. ${ }^{47}$ Esta transformación se apoyó en la tendencia de la espiritualidad cristiana encaminada hacia la introspección e interiorización individual, ${ }^{48}$ cuya característica fue considerada por Godínez como una experiencia personal e íntima de las religiosas, digna de ser narrada.

El universo del barroco de lo prodigioso sobrenatural heredó del maravilloso medieval algunas representaciones demoníacas adaptadas a la realidad, como animales u hombres negros o creaciones de seres imaginarios que lo representaban a través de bestiarios en los que se incluían grifos, dragones o duendes. ${ }^{49}$

La bestialidad como parte del orden natural tenía algunos elementos simbólicos relacionados con aspectos peyorativos o punitivos, representados por animales

46 Cervantes F. (1997). "El demonismo en la espiritualidad barroca novohispana". Manifestaciones religiosas en el mundo colonial americano, Vol I, Clara García Ayluardo y Manuel Ramos Medina (Cords). México: UIA, INAH, CONDUMEX, segunda edición, pp. 129-146.

${ }^{47}$ En su magistral trabajo DelumEAU, J. (1989), plantea que la emergencia de este personaje está vinculada a una lectura moderna de la Visión de San Pablo y las tentaciones de San Antonio y que fueron retomadas por la tradición reformista irlandesa, por ejemplo en la Visión de Tungal. Véase de este autor El miedo en Occidente, España: Taurus Alfaguara, pp.363-366. Cabe añadir, la importancia de la imprenta en la difusión del concepto y las categorías demonológicas que se plasmaron de manera plástica, pero también en libros de amplia circulación si nos atenemos a las reimpresiones en Alemania, Francia y España y cuyo papel debe ser dimensionado para el caso de la Nueva España.

${ }^{48}$ Este cambio a su vez se apoyó, según Cervantes en la transformación de un sistema basado en los siete pecados capitales a otro fundamentado en los diez mandamientos. Se puede decir que la obsesión por lo diabólico coincidió con el establecimiento del decálogo como base del sistema moral de la cristiandad. CERVANTES, F. (1994). The Devil in the New World.The Impact of Diabolism in the New Spain. New Haven: Yale University Press.También puede verse a MuCHEMBLED, R.(2002).Historia del Diablo, Siglos XII-XX. México: Fondo de Cultura Económica.

${ }^{49}$ Los demonios tuvieron cierta autonomía en el control de las fuerzas de la naturaleza por ejemplo al desafiar la ley de la gravitación, transferir a los hombres de un espacio a otro o metamorfosearlo y transmutarse ellos mismos en animales. Para el caso español véase José Luis Sánchez Lora, "Claves mágicas de la religiosidad barroca" en La religiosidad popular, Coordinado por Alvarez Santaló C. (1989). (Et, al.) Barcelona: Anthropos, editorial del Hombre, vol.II, pp.126-145. 
salvajes que por lo general encarnaban al miedo, ${ }^{50}$ al mal o a lo incierto. Dentro de este esquema la animalidad desempeñó una doble función. Por un lado, cuando el diablo se aparecía como animal que atacaba a la monja, representaba un atentado directo hacia su corporeidad individual y por el otro, un enfrentamiento moral contra la naturaleza humana al provocar con sus acciones que la religiosa perdiera la postura erguida o gesticulaciones que cuestionaban sus nociones civilizadoras al asumir conductas zoomorfas asociadas a la metáfora de la caída como inversión del mundo. ${ }^{51}$

El bestiario esbozado en la documentación permitía valorizaciones que expresaban una polivalencia semántica en el objeto representado. Lo que se temía no era tanto el animal sino sus acciones sobre el cuerpo de la víctima, haciendo alusión de animales agresivos que reflejaban sentimientos poderosos de bestialidad y de agresión, desafiantes del Orden Eterno. En los sueños o en la imaginación, estuvieron representados por invertebrados, grandes mamíferos y reptiles.

Al primer grupo de animales, los insectos, correspondió la animación acelerada del movimiento que era sinónimo de la agitación hormigueante o caótica. Era una proyección de la angustia del cambio y de la destrucción a partir de la huida del animal, asociado esto con las consecuencias de sus devastadoras acciones. ${ }^{52}$ Los insectos además de pulular tenían la posibilidad de introducirse en el cuerpo de su víctima con el objeto de causar dolor y agitación interna, desordenada. Debemos recordar que el infierno era interpretado por la iconografía como un lugar caótico y agitado.

El grupo representado por los animales de mayor talla lo encabezaba el caballo, que estuvo asociado con la cabalgadura fúnebre o infernal. ${ }^{53} \mathrm{En}$ el discurso del imaginario, el equino fue temido por su movimiento acelerado y por romper el orden cotidiano. Otro simbolismo animal ligado a los avatares de la naturaleza fue

${ }^{50}$ Desde la perspectiva psicoanalítica los animales que aparecen en las fobias zoológicas de los niños, son por lo general sustitutivos del padre. FreUd, S. (1989). "Una neurosis demoníaca en el siglo XVII". Psicoanálisis aplicado y técnica psicoanalítica. Madrid: Alianza Editorial, Libro de Bolsillo, Núm. 359, pp. 58-90.

${ }^{51}$ Delumeau, J. (1989). El miedo, pp.368.

${ }^{52}$ Una de las primitivas manifestaciones de la animalización fue el hormigueo atendiendo a la acción dinámica pululante, no al trabajo desempeñado por estos insectos propiamente. En un sentido positivo son ejemplo de diligencia y previsión. AuseJo, S. (1996). Diccionario de la Biblia, Barcelona: editorial Herder, p.872.

53 En el Apocalipsis el caballo de la muerte representa una notable similitud con el león y las fauces del dragón. Los caballos de los ángeles exterminadores tienen como "cabezas de león". 
el toro, que estuvo relacionado a través de su mugido con el trueno y el huracán en furia. Tanto el simbolismo taurino como el ecuestre fueron elementos relacionados con la angustia que generaban los elementos de la naturaleza, pues el estruendo podía interpretarse como manifestaciones de cólera divina y a veces con castigos colectivos. Como complemento de este bestiario de mamíferos, los caninos y los felinos concentraron los fantasmas terroríficos de la animalidad a través de sus movimientos, de sus acciones desgarradoras, de los sonidos, gruñidos y rugidos siniestros. En tanto animales mejor dotados de agresividad fueron evocados frecuentemente en forma de perros, leones y tigres.

Perteneciente a la especie de los reptiles, la serpiente de manera secular representó el miedo al mal y su aparición fue constante en el discurso. El simbolismo ofidio ha sido interpretado de múltiples formas. Oculta tras de sí el secreto de la muerte, de la fecundidad y del ciclo vital. ${ }^{54}$ Por su estructura corporal, por su forma oblonga y por su dinámica de desplazamiento era concebida como un animal que penetraba en la intimidad, atentando a la corporeidad de las religiosas, atormentando los sentidos y afectando casi siempre el centro de control sensorio motriz que era la cabeza. La emergencia del bestiario imaginario tuvo como uno de sus principales objetivos encarnar la lucha entre el bien y el mal. Gracias a la fortaleza de espíritu de las religiosas, a su virtual paciencia y a que Dios lo permitió, la concupiscencia fue vencida y la pureza y la castidad salvaguardadas y relatadas por el padre espiritual.

Gracias al desarrollo de ciertas virtudes, pero sobre todo a los diferentes grados de oración que Isabel había alcanzado, conoció el mundo teológico que se le deparaba después de vencer las tentaciones demoníacas y de sufrir intensas mortificaciones en su propio cuerpo. Ella había pasado por la vía purgativa en compañía del demonio y ahora conocía la iluminativa a través de visiones y revelaciones que se opacaban en momentos en que la contemplación oscura la invadía de un tedio y una indiferencia hacia su amado. Finalmente librando esos obstáculos comenzó a mostrar su inicio a la vida mística después de mantener momentos de contemplación infusa, coloquios afectuosos, requiebros dulces y afectos unitivos con que su querido Jesús le regalaba como muestra de su amor tierno, constante y cariñoso.

54 En la mitología antigua la serpiente era a menudo una imagen demoníaca o un monstruo cósmico del caos, pero en Gen 3, es más bien un símbolo de la sexualidad o de la ambición humana. El pocalipsis identifica a Satanás con la serpiente del Génesis. (Ap 12, 7 ss) cit. por Barbaglio,G.(1982). Nuevo Diccionario de Teología, Madrid: Ediciones Cristiandad, 1982, p.966. 
Godínez, deja entrever en esta última parte del texto, la clasificación de los conceptos y categorías -que serían profusa y doctrinalmente desarrolladas en su Práctica de la Theología Mystica- ${ }^{55}$ después de haber demostrado la posibilidad de encontrar espíritus proficientes e iluminados en el Nuevo Mundo, como fue el caso de su querida Isabel de la Encarnación.

\section{Del aporte hagiográfico. De la imaginación a las virtudes.}

El texto que hemos presentado deja ver por un lado que la mística y la ascética, como un modelo de actualización y adaptación de un nuevo lenguaje de signos y formas muestra que el programa humanista del renacimiento era compatible con el programa escolástico de la Edad Media. ${ }^{56}$ Por otro lado y de manera importante, ejemplifica cómo en el Nuevo Mundo al igual que en Europa, las tendencias espirituales que sintetizaban esa propuesta confluyeron y se reforzaron mutua y simultáneamente, en este caso la Ignaciana con la Teresiana. La espiritualidad Novohispana se nutrió básicamente de estas corrientes del pensamiento filosófico moderno occidental.

Los jesuitas a partir de una actualización metódica de la retórica divina elaborada por los monjes medievales, orientaron la interiorización de los sentimientos de la imagen de Dios (dolor y pecado). Lo hicieron retomando del método aristotélico el recurso de la persuasión, teatralizando, movilizando y dinamizando el cuerpo. Se logró de este modo la conjunción entre la ciencia antigua del cuerpo elocuente representado por la imagen de Cristo y el cuerpo de la monja, visible, sufriente, cercano a la muerte.

En la orientación espiritual de los carmelitas, la tendencia mística estuvo representada a través de las vidas de los Padres del desierto combinado con el indiscutible y renovador influjo Teresiano. Su especificidad proviene en gran medida de los orígenes eremíticos del Carmelo representados por los profetas San Elías y San Eliseo, que hicieron de la mortificación y la penitencia condiciones

55 Godínez. M.(1761)en el Libro primero de la Oración y Mortificación de Práctica de la Theología explica a manera de glosario los términos de la teología retomados de los místicos españoles e irlandeses y que son empleados por él. En el Libro segundo clasifica los tipos de oración y unión, en el Libro tercero da cabida al desamparo o a la noche oscura, retomando a los místicos carmelitas, Las divisiones de la contemplación, sus opciones y sus especies explicados en el Libro cuarto y que desarrolla más ampliamente en los Libros quinto y sexto. Finalmente en el Libro noveno se centra en las revelaciones y sus distinciones cuando son otorgadas por Dios o provocadas por el demonio.

56 Apostilla de O’Malley, J.W. SJ (2001). A Luce Girad, "Orígenes de la enseñanza jesuita". Colegios Jesuitas, México: Editorial Artes de México, Revista-libro, Núm.58, pp.30. 
imprescindibles en la búsqueda de perfección mientras que, a través del Camino de perfección se concretaron las virtudes y cualidades que definirían en cierto modo a la Orden: la humillación voluntaria y la capacidad de aceptar los sufrimientos siguiendo el modelo de la pasión de Cristo. Otra característica, en continuidad con la tradición helénica fue la búsqueda de la pureza y la castidad encarnadas estética y narrativamente por las grandes figuras del Carmelo moderno.

La aplicación, por parte de confesores y directores espirituales, de estos lineamientos doctrinales en combinación con los métodos de introspección y espiritualización de los sentidos, en donde la imaginación fue un elemento fundamental para la "composición del lugar" hizo factible un ascetismo que parecía racionalmente justificado. La monja, al comprometerse a disponer de su propia vida de tal manera que ésta se adecuara al proyecto Divino, aceptaba la necesidad de ser guiada para poder reconocer sus posibilidades espirituales y encausarlas a la búsqueda de los caminos necesarios y así ser partícipes del orden de la creación y la salvación. Éstos se encontraban a través de la experiencia individual del vivir cotidiano de las virtudes.

Toda esta activación teórica y práctica tuvo como resultado el surgimiento de textos que expresaban, narraban y permitían organizar y argumentar las posibilidades de santidad en el Nuevo Mundo, tan buscadas por Palafox y Godínez. De manera paralela a la conjunción doctrinal, para la primera mitad del siglo XVII fue perceptible una actualización de los requerimientos de canonización y para esto fue necesario activar un repertorio de virtudes como criterios de santidad dejando para otro objetivo la comprobación de milagros. ${ }^{57}$ Estos lineamientos influyeron en el tipo de orientación de la lectura y escritura y el proceder místico, pues ciñeron los parámetros de la ortodoxia católica barroca, percibiéndose tendencias a una uniformidad del género hagio-biográfico espiritual en torno a la moralización de los comportamientos. Godínez retomó parcialmente esta moderna posibilidad literaria en la última parte del texto que aquí transcribo y la continuó, también de manera mesurada en la redacción de su Práctica de la Theología Mística, donde el maligno no fue más el personaje central del acto demonológico como lo había sido, sino que quedó circunscrito a lo largo de los capítulos, a garantizar el cumplimiento de las virtudes. Como propuesta interpretativa se puede pensar que en este modelo,

${ }^{57}$ Desde el siglo XII se le concedió al papa la máxima autoridad en el reconocimiento de las canonizaciones y del culto de los Siervos de Dios. Hasta 1525 bajo el pontificado del papa Urbano VIII la cuarta romana orientó una investigación más crítica sobre la vida, virtudes y milagros sobre cualquier candidato a beatificación. Aguilera M. R. y GARIBAY, A. J. (1997). Manual de Archivistica Eclesiástica, México: Instituto de Estudios Históricos Carlos de Sigüenza y Góngora, A.C. y Colegio Nacional de Archivistas de México, A.C., pp. 43-46. 
apenas tocado por el jesuita pero que se impuso en los textos posteriores a 1650, lo místico tendía ya a disociarse de lo extraordinario y la imaginación quedaría sujeta a la memoria.

La "Vida" de Isabel narrada y escrita por el jesuita nunca se publicó y fue retomada y modificada entre 1646 y 1653 por fray Agustín de la Madre de Dios a quien fue encargada la redacción de la crónica colonial más importante de los carmelitas $^{58}$ y cuya edición fue imposible. ${ }^{59}$ Más tarde, el licenciado Pedro de Salmerón, presbítero y capellán de las carmelitas la editó en 1675 con el objetivo de difundir la "Vida" de esta venerable religiosa. ${ }^{60}$ Él también transcribió la totalidad del texto de nuestro jesuita y al igual que el carmelita, le introdujo modificaciones retóricas añadiendo únicamente una tercera parte dedicada a las devociones a quien la monja tuvo especial afecto. El rescate verdadero de la "Vida" de Isabel se debió sin lugar a dudas al Padre Godínez quien tan bien la conoció y quiso y a quien paradójicamente sus cronistas y editores no dedicaron siquiera una línea reconociendo su trascendente labor en el campo de la cultura teológica novohispana.

\section{BIBLIOGRAFÍA}

Aguilera Murguía, Ramón y GARIBAY, Álvarez Jorge (1997). Manual de Archivistica Eclesiástica. México: Instituto de Estudios Históricos Carlos de Sigüenza y Góngora, A.C. y Colegio Nacional de Archivistas de México, A.C. Agustín de la Madre de Dios, fray (1986). Tesoro escondido en el Monte Carmelo. Versión paleográfica, introducción y notas de Eduardo Báez Macías, México: UNAM.

Alfaro, Alfonso. (2004) "Las formas del espíritu". Arte y espiritualidad jesuitas. México: Artes de México, Revista-libro, Núm. 70, p.6.

58 Agustin de la Madre de Dios, fray (1986). Tesoro escondido en el Monte Carmelo. Versión paleográfica, introducción y notas de Báez Macías, Eduardo, México: UNAM. El carmelita dedica a la trascripción total del texto del padre Codines, 33 páginas aproximadamente sin mencionar su nombre. La paginación y la temática, estuvieron sujetas a múltiples modificaciones en el ordenamiento interno del texto de la crónica. Véanse pp.330 a 363.

59 fray Agustín fue juzgado por las autoridades de su orden acusado de sublevación por la redacción de su Discurso apologético a favor de los criollos del reino Mexicano contra una ley que tienen los frailes carmelitas de no admitirlos a su religión. Agustín de la Madre de Dios (1986). Ibidem. p. XV.

${ }^{60}$ Vida de la Venerable Madre Isabel de la Encarnación, Carmelita Descalza natural de la ciudad de los Ángeles Compúsola el licenciado Pedro de Salmerón, presbitero natural de esta ciudad. México: Francisco Rodríguez Lupercio, impresor, 1675, 120 ff. 
AhlgRen, Gillian. T.W. (1996). Teresa of Avila and the Politics of Sanctity. Ithaca and London: Cornell University Press.

Alvarez Santaló C. (1989). (Et, al.) Barcelona: Anthropos, editorial del Hombre, vol.II.

ARMACANQUI-Tipacti, Elia (1999). Sor María Manuela de Santa Ana: una teresiana peruana. Cuzco: Centro de estudios Regionales Andinos "Bartolomé de Las Casas".

AuseJo, S. (1996). Diccionario de la Biblia. Barcelona: editorial Herder.

BRADING, David ( 2001).“ La patria criolla”. Colegios Jesuitas. México: Editorial Artes de México, Revista-libro, Núm.58, p.64.

Barbaglio, G.(1982). Nuevo Diccionario de Teología. Madrid: Ediciones Cristiandad, 1982.

BARRIOS, Alberto (2002). Introducción a la lectura de Santa Teresa. Madrid: editorial Espiritualidad, Segunda Edición.

Bravo, Dolores (1984). Ana Rodríguez de Castro y Aramburu, ilusa, afectadora de santos, falsos milagros y revelaciones divinas. Proceso Inquisitorial en la Nueva España (siglos XVIII y XIX). México: Instituto Nacional de Bellas Artes/SEP Cultura, Universidad Autónoma Metropolitana.

Bynum, W. Carolyne (1984). Jesus as Mother. Studies in the Spirituality of the High Middle Ages. Los Angeles: University Press.

CALINO, Cesar JS. (1794). Discursos escriturales y morales para útil y provechoso entretenimiento de las religiosas. Escritos en Italiano y traducidos al español por el padre Domingo Ascarza de la misma Compañía. Madrid: Imprenta de Joseph Doblado.

CerteaU, Michel de JS. (1992). The Mystic Fable. Chicago and London: The University of Chicago Press.

CERTEAU, Michel de JS. (2004). "El espacio del deseo". Arte y espiritualidad jesuitas. México: Artes de México, Revista-libro, Núm. 70, pp. 39-47.

CERVANTES, Fernando (1994). The Devil in the New World.The Impact of Diabolism in the New Spain. New Haven: Yale University.

CERVANTES, Fernando (1997). "El demonismo en la espiritualidad barroca novohispana". Manifestaciones religiosas en el mundo colonial americano, Vol I. Clara García Ayluardo y Manuel Ramos Medina(Cords). México: UIA, INAH, CONDUMEX, segunda edición, pp. 129-146.

Chinchilla PAWling, Perla (2001). "La composición del lugar, de la Imaginación a la memoria". Historia y Grafía. México, UIA, Núm.16, pp.15 -43

DELUMEAU, Jean (1989). El miedo en Occidente, España: Taurus Alfaguara.

DRAGO Margarita (2000). "Sor María de Jesús Tomellín (1579-1637) Concepcionista poblana: la construcción fallida de una santa".Tesis $\mathrm{PhD}$. University of New York, 
DURAN, Norma (2003). "La construcción de la subjetividad en las hagiografías, un caso: Sebastián de Aparicio". Camino a la Santidad, Siglos XVI-XX. Manuel Ramos Medina, (coord.). México: Centro de Estudios de Historia de México, Condumex, pp.165-196.

FREUD, Sigmund (1989). "Una neurosis demoníaca en el siglo XVII".

Psicoanálisis aplicado y técnica psicoanalítica. Madrid: Alianza Editorial, Libro de Bolsillo, Núm. 359, pp. 58-90.

Godínez, Miguel Práctica de la Theología Mystica. Pamplona: En la oficinas de los Herederos de Martínez, 1761.

GonZALbo Aizpuru, Pilar (2002) Reseña a Asunción Lavrin y Rosalva Loreto L. (eds.). Monjas y beatas. La escritura femenina en la espiritualidad barroca novohispana. Estudios de Historia Novohispana, Instituto de Investigaciones Históricas, UNAM, México, Núm. 27, julio-diciembre, pp.243-249.

HolleR, Jacqueline (1993). "I, Elena de la Cruz: Heresy and gender in México City, 1568". Journal of Canadian Historical Association, Núm.4, pp. 143-60; (1997).

HoLLER, Jacqueline (1997) "More Sins than the Queen of England: Marina de San Miguel Before the Mexican Inquisition". Mary Giles (ed). Women in the Inquisition: Spain and the New World. Baltimore: Johns Hopkins University Press, pp. 209-228;

Holler, Jacqueline (2000). "The Spiritual and Physical Ecstasies of a SixteenthCentury, Beata: Marina de San Miguel Confesses Before the Mexican Inquisition (México, 1598)". Richard Boyer and Geoffrey Spurling. (Eds). Colonial Lives: Documents on Latin American History, 1550-1850. New York: Oxford University Press, pp. 77-100

Howe, Elizabeth T. (2004) The Visionary Life of Madre Ana de San Agustin. Suffolk:Tamesis.

ITURBURU, Fernando (2001). (Auto) biografía y misticismo en la Colonia: la relación escrita por madre Josefa de la Providencia sobre madre Antonia Lucía Mandonado. New Orleans: University Press of the South.

LAVRIN, Asunción (En prensa) ."Female Visionaries and Spirituality in New Spain". Susan Schoroeder y Stafford Poole.(Eds). Mexico's Transformative Church:Colonial Piety, Pogroms, and Politica Delaware: Scholarly Resources Inc.

LAVRIN, Asunción y LORETO, L. Rosalva (2002). (Eds). Monjas y betas. La escritura femenina en la espiritualidad barroca Novohispana. Siglos XVII-XIX. México, Universidad de las Américas, Puebla/Archivo General de la Nación, $275 \mathrm{pp}$.

LORETO López., Rosalva (1998). "Las pruebas del milagro en el proceso de beatificación de la Madre María de Jesús en los siglo XVIII y XIX", en Manuel 
Ramos Medina, compilador, Historia de la Iglesia en el Siglo XIX. México: E1 Colegio de México, El Colegio de Michoacán, Instituto Mora, UAM-

IZTAPALAPA, CONDUMEX, pp. 351-368.

LORETo López., Rosalva (2002). "The Devil, Women, and the Body in

Seventeenth-Century Puebla Convents". The Americas, Vol. 59, Núm.2,

October, pp. 181-199.

MCKNIGHT Kathryn Joy .(2000). The Mystic of Tunja; The Writings of Madre Castillo, 1671-1742. Amherst: University Press.

MUCHEMBLED, Robert (2002).Historia del Diablo, Siglos XII-XX. México: Fondo de Cultura Económica.

Nuevo diccionario de la lengua castellana. París: Librería Bouret e Hijo, 1877.

O’ Malley John W. SJ. (2001). "Orígenes de la enseñanza jesuita”. Colegios Jesuitas, México: Editorial Artes de México. Revista-libro, Núm.58, pp.30.

PELIKAN, Jaroslav (1985). The Christian Tradition. A History of the Development of Doctrine Reformation of Church and Dogma (1300-1700). Vol.4. Chicago: The University of Chicago Press, pp.63-68.

PFEIFFER, Henrich SJ. (2004). "Los jesuitas arte y espiritualidad". Colegios jesuitas, México: Artes de México, Revista-libro, Núm. 58, pp. 47-51.

PIKE, Nelson (1992), Mystic Union, An Essay in the phenomenology of Mysticism. Ithaca:Cornell University Press.

PINAMONTI, Juan Pedro JS. (1733).. La religiosa en soledad. Obra en que se expone alas religiosas el modo de emplearse con fruto en los ejercicios espirituales de San Ignacio de Loyola. Traducida en español por el padre Martín Pérez Culla, De la misma Compañia. Madrid: Antonio Sanz, Impresor de libros.

POUTRIN, Isabel (1995). Le voile et la plume. Autobiographie et sainteté dans L'Éspagne moderne. Madrid: Casa de Velásquez.

Ramos Medina, Manuel (1997). Místicas y descalzas. México: Condumex.

RANF, Patricia A Woman's Way, The forgotten History of Women Spiritual Directors. New York:Palgrave, 2000,págs.

RoDRÍGUEZ, Alonso JS. (1727). Exercicio de Perfección y virtudes cristianas. Madrid: Francisco del Hierro, Impresor, 3 tomos.

RuBIAL, Antonio (2002). "Josefa de san Luis Beltrán, la cordera de Dios: escritura, moralidad y gestualidad de una visionaria del siglo XVII Novohispano. 1654". Lavrin, A. y R, Loreto. (Eds.) Monjas y beatas. La escritura femenina en la espiritualidad barroca Novohispana. Siglos XVII-XIX, México, Universidad de las Américas, Puebla/Archivo General de la Nación, pp.161-204.

SAN Juan de la Cruz (1984). Subida del Monte Carmelo. Noche Oscura. Cántico Espiritual. Llama de Amor Viva. México: Editorial Porrúa, S.A.

SANTA Teresa de Jesús (1995). Libro de la Vida.. Barcelona: Editorial Altaya, 
SUIRE, Éric (2001) "La sainteté Carmélitaine d'après la littérature hagiographique de XVIIe-XVIIIe Siècles". Carmes et Carmelites en France du XVIIe siècle a nos jours. Lyon: Actes du Colloque de Lyon (25-26 septembre, 1997), pp.171189.

TANQUeReY (1930). Compendio de Teología, Ascética y Mistica: Madrid: Sociedad de San Juan Evangelista.

Troncarelli, Fabio (1999). La Spada e la Croce Guillén Lombardo e l'Inquizicione en México. Roma: Salermo Editorie.

UNDERHILL, Evelyn (1990). Mysticism. New York: Doubleday.

VUACHEZ,André (1989). "La hagiografia entre la crítica histórica y la dinámica narrativa”. La Vie Spirituelle. Paris: Núm. 143, pp. 251-260.

Weber, Alison (1990). Teresa of Avila and the Rhetoric of Feminity. Princeton: Princeton University Press.

WEISSNER.W. M.D. SJ. (1992), Ignatius of Loyola.The Psychology of a Saint. New Haven: Yale University Press,

Zambrano, F. SJ. (1967). Diccionario Bio-bibliográfico, de la Compañia de Jesús en México, Tomo VII, 1600-1699, México: Editorial Jus, S.A. 
